\title{
MOOC-based flipped learning in higher education: students' participation, experience and learning performance
}

Kai Wang and Chang Zhu* (D)

\author{
* Correspondence: chang.zhu@vub. \\ be \\ Department of Educational \\ Sciences, Vrije Universiteit Brussel, \\ Pleinlaan 2, B-1050 Brussel, Belgium
}

\begin{abstract}
Relying on advanced network technologies, Massive Open Online Courses (MOOCs) can support the transformation and deep construction of high-quality open courses. However, with the use of MOOCs in many universities and colleges, new issues have emerged. MOOCs are not specifically designed for local conditions. Researchers lack understanding of the effectiveness of using shared MOOCs in traditional university teaching. The purpose of this study was to analyze the effectiveness of MOOC-based flipped learning and to propose clear reuse guidelines for MOOCs in the traditional university education. We conducted a quasi-experiment in an inorganic chemistry course. The results were presented in terms of learners' participation and learning performance, and a post-task survey and interviews were also conducted to investigate the students' experiences in order to include these experiences in design and research plans of MOOCs-based flipped learning. The results showed that students in the MOOC-based flipped classroom on average performed better than those in the traditional classroom. However, no changes in self-efficacy and selfregulated learning were detected after the end of the course. In addition, the quantitative and qualitative data combined indicated that most students had a favorable experience of the flipped classroom, in terms of student-student interaction, available learning materials, and active learning results. Implications for MOOC integration are discussed.
\end{abstract}

Keywords: MOOCs, Flipped learning, Higher education, Learning performance

\section{Highlights}

- This paper presents the use of shared MOOCs to foster flipped learning among higher education students.

- We compared learning performances in an MOOC-based flipped classroom and a traditional class.

- The use of a MOOCs in flipped learning had no effect on students' self-regulated learning (SRL) and self-efficacy (SE).

- The study provides initial evidence with which to evaluate students' perceptions of MOOC-based flipped learning. 


\section{Introduction}

In recent years, the information technology and internet technology in particular, has developed rapidly, and our society has entered the "Internet+" era. In the field of education, the information technology has increasingly and profoundly affected the development and reform of education in China. In 2011, Salman Khan made a brilliant speech on "reproducing education with video" at TED, drawing the attention of educators around the world to "micro-lectures" and "flipping classroom". Due to the rise of Massive Open Online Courses (MOOCs), a large number of micro-lectures have been developed. On the one hand, MOOCs offer quality courses from top universities to any learner in the world. On the other hand, they can be redeployed as supplementary residential courses in which students first use MOOCs to interact with online courses and then attend face-to-face classes to focus on the specific questions they have. Researchers and educators are convinced that flipped classroom practices based on open online videos can promote student participation, resulting in better learning outcomes (Kong, 2014; Tune, Sturek, \& Basile, 2013). In addition, some researchers have shown the impact of flipped learning on student-centered learning variables, such as self-efficacy (SE) and selfregulated learning (SRL) (Lai \& Hwang, 2016; Lin, Hsia, Sung, \& Hwang, 2018).

Moreover, typical flipped learning assumes a common designer of both face-to-face and online learning, namely the on-campus teacher. MOOCs offer a new option for flipped learning design. Teachers can flip their courses with existing MOOCs. In this approach, students in an on-campus course are asked to participate in MOOCs developed by other institutions. MOOCs are a relatively new technology, and they have not been "normalized" in everyday practice (Bax, 2018). More and more MOOC researches are focusing on the use of MOOCs as part of a broader approach to education. Some work has been carried out to use MOOCs to support campus-based teaching. However, MOOC-based flipped learning (MBFL) is still in its early stages. There has been a lack of analysis of its feasibility and advantages, from pedagogical and psychological perspectives though there are few studies of students' perceptions and behaviors, or comparisons between MBFL and traditional learning. The present study is a quasiexperimental investigation into the integration of shared MOOCs into traditional classroom practices in an undergraduate course. Specifically, it explores students' experiences and learning performance in this emerging form of learning. Prior to the introduction of the methodology, relevant literature on MOOCs and flipping classroom practices will be summarized.

\section{Literature review}

\section{MOOCs}

MOOCs are online courses designed for open, unrestricted participation through the internet (Kaplan \& Haenlein, 2016). Downes (2008) introduced the term MOOC when they described an experimental online course called "Connectivism and Connective Knowledge". This course quickly caught the attention of the world, and world-class universities have been working increasingly with MOOC providers and service providers to offer MOOC courses (Li, Zhang, Bonk, Guo, \& Guo, 2015). After some startups (e.g. Udacity, Coursera, edX, NovoEd, etc.) in the United States, other initiatives at 
the national level have followed, for example, MiríadaX in Spain, FutureLearn in the United Kingdom, XuetangX in China, and umbrella initiatives at the European level, e.g. OpenUpEd.

As more and more universities have experimented with $\mathrm{MOOC}$ integration, various methods for MOOC adjustment, integration, and research have been adopted (Bruff, Fisher, McEwen, \& Smith, 2013; Firmin et al., 2014). Martin (2012) advocated the use of flipped classrooms as a strategy for MOOC blended learning. DeBoer, Ho, Stump, and Breslow (2014) worked with teachers to investigate the behavior and satisfaction of MOOC users. Other studies have applied quantitative methods to learners' digital traces in the context of big data (Breslow et al., 2013). However, while gaining meaningful and significant insights into the users' online learning behavior, the set of analytical methodologies is essentially focused on the macro level of the entire learning community of the course, and is less suitable for understanding a smaller user base.

\section{MOOC-based flipped learning}

Jonathan Bergmann and Aaron Sams launched the inverse instruction methodology (IIM) or "Flipped Classroom" in 2007 (Tucker, 2012), in which the traditional teaching structure of acquiring knowledge in the classroom and internalizing it at home has been changed to a new teaching structure based on learning outside the classroom and deep discussion of the topic, peer collaboration, and personalized teacher guidance in the classroom (Francl, 2014). Advocates of flipped classroom teaching claim that while traditional teaching can help students acquire new knowledge effectively, the speed of teachers' lectures in the classroom sometimes brings problems to students' learning. For some students, the pace of teaching is too slow or there is no new content. However, other students who lack sufficient prior knowledge may find the same teaching content difficult to understand.

Moreover, teachers often assign assignments and ask students to complete them after school, which many students perceive to be an arduous, frustrating and confusing task. Bulfin, Pangrazio, and Selwyn's (2014) critical analysis of the 20122013 MOOC discourse highlights the broad social struggle for education and digital technology. As such, these discussions raise important debates about the role of technology and openness in education that dissipate as the conventions of MOOCs are normalized and assimilated into educational practices. Some scholars have asserted that researchers should not only collect data on existing practices, but also develop a vision for future education, for example, by exploring unresolved issues related to MOOCs and other more open forms of education, such as assessment, certification and teaching methods (Fischer, 2014).

\section{Students' participation}

In flipped classrooms, students learn alongside their classmates in a more interactive and learner-centric educational environment. Teachers are not "sages on the stage", but work with students to ensure that they have assimilated the necessary curriculum concepts. The class time is also used for student-centered learning activities such as exploring and problem-solving, and for one-on-one instruction by teachers to help students overcome points of confusion, enabling them to become more interactive in 
the classroom (Moraros, Islam, Yu, Banow, \& Schindelka, 2015). The typical practice of flipping the classroom combines micro-lectures and practices based on the theory of humanistic learning to achieve "re-education with video". A study of Kim, Patrick, Srivastava, and Law (2014) compared student performance in flipped-learning and traditional classes. Student performance was enhanced using the flipped classroom methodology with $83 \%$ of the students gaining a C grade or better, compared to $56 \%$ for the class using a traditional course methodology. However, there are little studies comparing student grades in a traditional classroom with those in a flipped classroom that incorporates MOOCs technology.

\section{Students' experience and learning performance}

Regarding student experiences, various studies have suggested that students hold a positive view of the flipped classroom methodology. For example, a report featuring 142 students from two courses showed that students preferred the IIM to traditional pedagogical methodologies (Gilboy, Heinerichs, \& Pazzaglia, 2015). In a study of student preferences in STEM courses, Sowa and Thorsen (2015) showed that students not only preferred the IIM environment to a traditional setting, but in most cases, felt that the teaching tools used in the flipped classroom setting were useful learning tools. In a previous study (Roach, 2014), participants were asked to point out the benefits of the IIM, and they emphasized that the ability to revisit the media-type course materials allowed them to overcome difficulties in the traditional learning process. Conversely, Chen, Wang, Kinshuk, and Chen (2014) found that some students struggled to adapt to flipped learning and were left behind in class group discussions because they had not watched any of the instructional videos before the class. Therefore, a comprehensive study of the various components of the flipped model is essential.

In parallel with its increased use in educators' practices, the literature on flipped learning has grown rapidly in recent years (Hao, 2016; Wu, Hsieh, \& Yang, 2017). In comparison to online learning and traditional learning, flipped classrooms produce better final exam scores. Researchers, such as Egbert, Herman, and Lee (2015) and Leis, Cooke, and Tohei (2015), have asserted that flipped learning is very helpful for students' language study. Strayer (2012) pointed out that the flipped-classroom approach could help students become more open to collaborative learning in a statistics course. A growing body of research has focused on the design of flipped classrooms emphasizing how the flipped classroom promotes student participation and better learning outcomes (Geist, Larimore, Rawiszer, \& Al Sager, 2015; Harrington, Bosch, Schoofs, BeelBates, \& Anderson, 2015).

\section{The role of student variables}

The present study focuses on the effect of MOOC-based flipped learning on two student-centric variables, SE and SRL. SE refers to an individual's belief in their ability to perform the actions necessary to produce a particular performance achievement (Bandura, 1982). SE reflects the confidence in the ability to control one's motivations, behaviors, and social environment. Lai and Hwang (2016) claimed that the flipped classroom approach is significantly beneficial to students' SE. A similar effect was noted in a study where students taught by the flipped learning approach outperformed those 
learning with the traditional instruction in terms of SE (Lin et al., 2018). SRL is a positive and constructive process in which an individual takes control of his/her own learning in terms of cognition, motivation, and behavior (Zimmerman, 2001). In the past decade, the importance of learners' SRL skills has been emphasized in Internet learning environments (Chang, 2007; Littlejohn, Hood, Milligan, \& Mustain, 2016; Vighnarajah, Wong, \& Abu Bakar, 2009). Previous studies have investigated the effects of context and strategic intervention on SRL (e.g. Yang, 2006). Barber, Bagsby, Grawitch, and Buerck (2011) examined the role of technology in facilitating self-regulated learning.

Research objectives and research questions The purpose of this study was to investigate what effect MOOC-based flipped learning (MBFL) would have on students' learning performance in an undergraduate inorganic chemistry course. Specifically, the study had four main research questions: (1) To what extent do students participate in MBFL, in terms of watching micro-lectures and doing online exercises? (2) Will students' SE and SRL in MBFL setting increase after the completion of the course? (3) What differences in student learning performance can be observed between classes adopting MBFL and traditional learning after the course? (4) What are students' reported experiences of MOOC-based flipped classroom practice after the course?

\section{Methodology}

In order to test and compare the effectiveness of MOOC-based flipped learning, a quasi-experimental design was employed in this study. In addition, the combination of quantitative and qualitative data collection allows a more comprehensive understanding of students' experiences and perceptions in the MOOC-based flipped-learning environment. Our data include three types. First, students' participation, in terms of watching micro-lectures and doing online exercises. Second, students' experiences and (pretest and posttest) learning performance. Third, interview data from students in the quasiexperimental group.

\section{Participants and settings}

We selected two classes of first-year undergraduate students from the 2017 chemistry program at the Shaanxi Preschool Teachers College as the research subjects. The numbers of students in the two classes were 36 and 37. The majority of the students were first time users of MOOCs. The MOOC-based flipped learning was used on the group of 37 students and the control group included 36 students. Two groups were taught by the same teacher.

The inorganic chemistry course was a four-credit course and was offered during the winter semester of 2017. It was taught twice a week on Tuesday and Friday, $90 \mathrm{~min}$ at a time. This semester-long course run for a total of 18 weeks. Our quasi-experiment started from the 12th week and continued until the end of the semester (6 weeks in total). On the Chinese University MOOC platform, many universities offer similar courses. After discussing with the teacher, we selected to use the inorganic chemistry course developed by Dalian University of Technology. This course included 11 chapters, each chapter contained six to eight micro-lectures, and the length of each microlecture was approximately $12 \mathrm{~min}$. 


\section{Learning process and activities}

After the quasi-experiment began, each student in the flipped classroom needed to register an account on the Chinese university MOOC platform in order to view the micro-lectures and finish the online exercises. The flipped classroom involved two parts: pre-class and class activities. Before each class, students were asked to watch two or three micro-lectures on the Chinese university MOOC platform. Figure 1 is an example of a micro-lecture. Students were required to complete ten exercises after watching the micro-lectures. Since the teacher

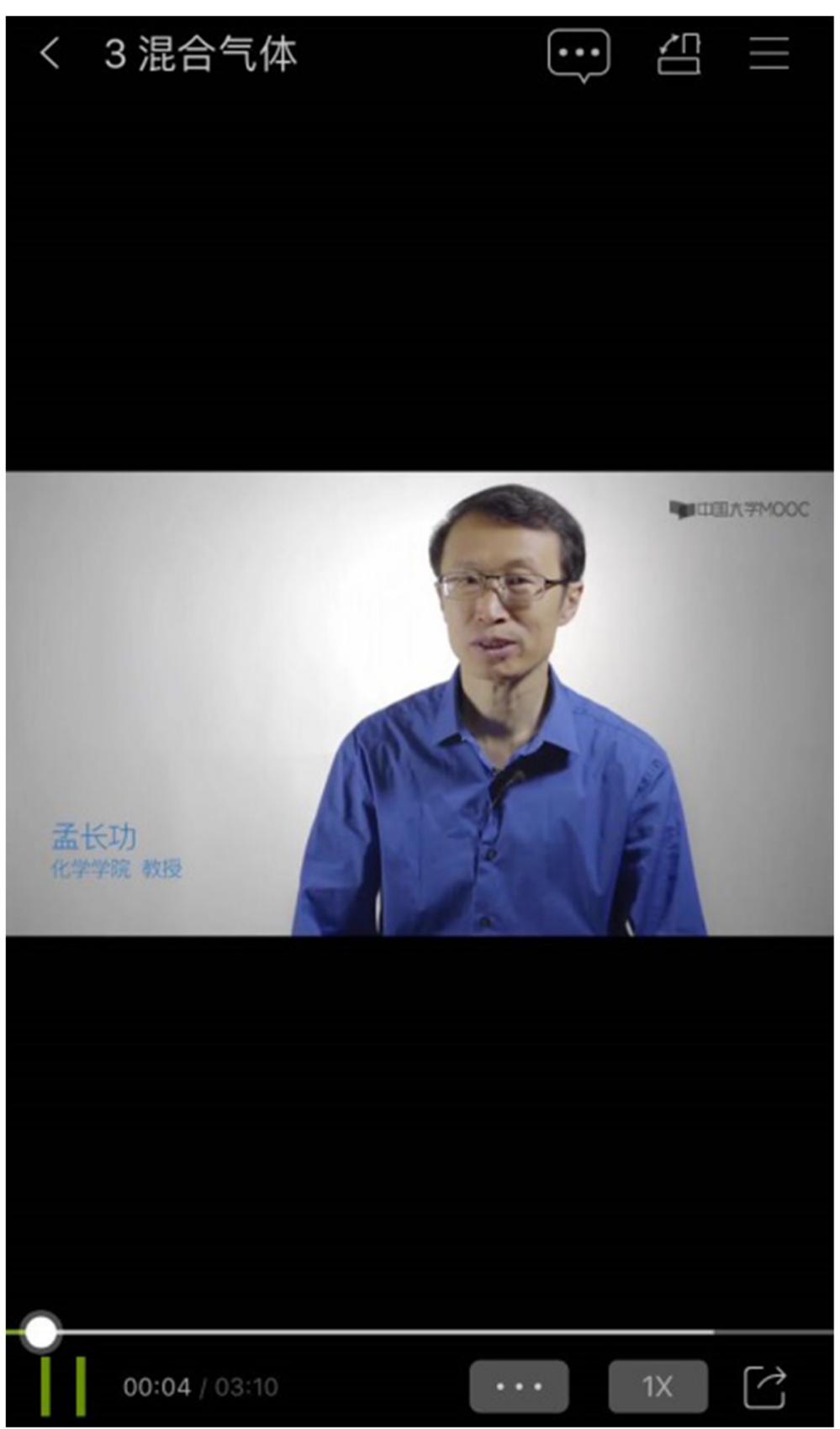

Fig. 1 An example of a micro-lecture with slides. The video screenshot of the chemistry course is taken from the Chinese university MOOC platform. Students can watch the video repeatedly by clicking the pause, forward and rewind buttons at the bottom, and also adjust the video playback speed 
in the quasi-experimental class did not have permission to view the students' data on the platform, the students needed to manually record their incorrect exercise responses after completing the task. Exercises from the platform are shown in Fig. 2. During the classes, the students was divided into seven groups of around five students. During the first 45 min, the students participated in a group discussion to share their opinions and discuss the reasons for their incorrect responses to the online exercise. During the discussion, the teacher gave individual guidance to students who asked questions. Student interactions are shown in Fig. 3. After the discussion, students needed to submit the questions and topics that they had not yet understood. Then, during the second $45 \mathrm{~min}$, the teacher gave a focused explanation of the topics put forward by each group. Correspondingly, students in the traditional class accepted traditional face-to-face instruction during $90 \mathrm{~min}$. During the traditional course, teacher directed the instruction, lecture or demonstration, and students watched and listened and took notes.

\section{Instruments}

At the beginning and end of the study, students were presented with a research instrument consisting of two subscales focusing on SE and SRL (Lee \& Tsai, 2011; Zhao, Lu, Huang, \& Wang, 2010). Learner SE was measured by six items and a sample statement was "I feel confident watching the micro-lectures." Learner SRL was measured by seven items and a sample statement was "I will use appropriate learning strategies in daily study." The questionnaire followed a five-point Likert-type scale.

In order to gauge students' experience of MOOC-based flipped learning, a post-task questionnaire survey was also conducted. The questionnaire was adapted from the Student Perception of Instruction Questionnaire (SPIQ) by (Johnson L, Renner J: Effect of the flipped classroom model on a secondary computer applications course: Student and teacher perceptions, questions and student achievement, Unpublished). Our questionnaire included 11 closed-ended items regarding the students' views on course content and delivery, assessment and evaluation, as well as communication and learning experiences. Students accepted a survey at the end of the course. The answer to each question was designed using a fivepoint Likert scale. These questions are listed in Table 1.

\section{Interviews}

Qualitative data were obtained by semi-structured face-to-face interviews after the flipped-learning experience. The interviews were based on six guiding questions:

(1) What are your views on flipped learning in general? (2) Do you like the micro-lectures and online exercises? (3) Do you think the face-to-face sessions are useful? (4) Did the flipped learning affect your learning motivation and attitude? (5) What were the main problems you encountered in the flipped learning experience? (6) What suggestions do you have for a better flipped-learning experience? The interviews ranged from $20 \mathrm{~min}$ to $40 \mathrm{~min}$. All interviews were audio-recorded, annotated, and transcribed for further data analysis.

\section{Learning performance}

To examine the level of change due to the variables measured in the quasiexperimental conditions, learning performance was measured by using the final score at the end of the semester. Final score is standardized on a $0-100$ point scale. 


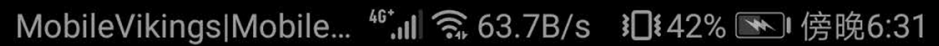 \\ 题目 $1 / 15$}

1、单选 如果体系经过一系列变化，

最后又变到初始状态，则体系的

) 0

$$
\begin{aligned}
& \text { A }{ }^{1}-\mathrm{W}, \Delta \mathrm{U}=\mathrm{Q}+\mathrm{W}, \Delta \mathrm{H}=0 \\
& \mathrm{Q}{ }^{1} 0, \mathrm{~W}^{1} 0, \Delta \mathrm{U}=0, \Delta \mathrm{H}=\mathrm{Q} \\
& \mathrm{Q}=-\mathrm{W}, \Delta \mathrm{U}=\mathrm{Q}+\mathrm{W}, \Delta \mathrm{H}=0 \\
& \mathrm{D}=0, \mathrm{~W}=0, \Delta \mathrm{U}=0, \Delta \mathrm{H}=0 \\
& \text { D } \mathrm{T} \text {-题 }
\end{aligned}
$$

Fig. 2 An example of an online exercise from a selected course. Each unit of the course platform has a matching exercise test, submission deadline and corresponding scores. Students can use those online exercises to test the effect of watching the video 


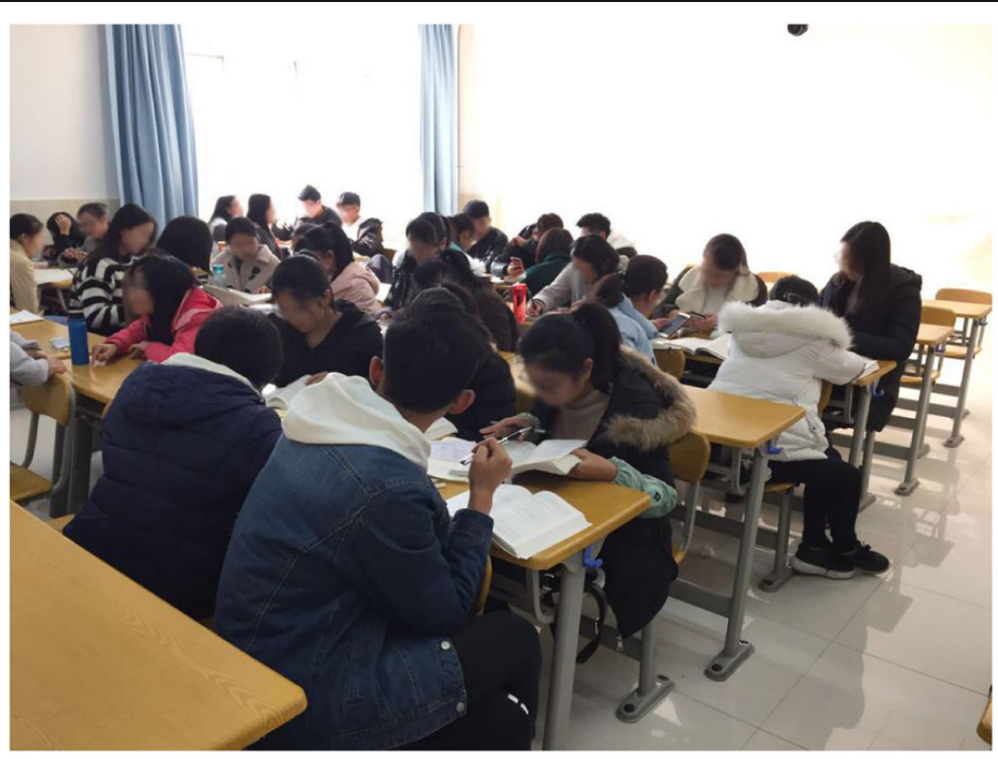

Fig. 3 Group discussion in the face-to-face classroom. In the first $45 \mathrm{~min}$ of face-to-face classroom teaching, each group of students to discuss the problems they can't solve when they watch videos and do online exercises before class. Also, each group has a team leader who is responsible for group discipline

Table 1 Post-task survey items and results concerning students' experience of the MOOC-based flipped learning

\begin{tabular}{|c|c|c|c|c|}
\hline \multirow[t]{2}{*}{ Items for response } & \multicolumn{4}{|c|}{ Students' response (\%) } \\
\hline & Negative & Neutral & Positive & $\begin{array}{l}\text { Mean } \\
(S D)\end{array}$ \\
\hline Q1. During the last 6 weeks, I communicated a lot with other students. & 13.9 & 30.6 & 55.5 & $\begin{array}{l}3.44 \\
(0.86)\end{array}$ \\
\hline Q2. During the last 6 weeks, I talked a lot with the teacher & 38.9 & 38.9 & 22.2 & $\begin{array}{l}2.87 \\
(0.88)\end{array}$ \\
\hline Q3. During the last 6 weeks, I had to work hard on this course. & 5.6 & 13.9 & 80.6 & $\begin{array}{l}4.03 \\
(0.85)\end{array}$ \\
\hline Q4. During the last 6 weeks, I have learned a lot on this course so far. & 16.7 & 19.4 & 63.9 & $\begin{array}{l}3.69 \\
(0.93)\end{array}$ \\
\hline $\begin{array}{l}\text { Q5. During the last } 6 \text { weeks, the assignments and projects I have worked } \\
\text { on for this course have dealt with real life applications and information. }\end{array}$ & 11.2 & 36.1 & 52.8 & $\begin{array}{l}3.57 \\
(0.89)\end{array}$ \\
\hline $\begin{array}{l}\text { Q6. During the last } 6 \text { weeks, the availability of course materials, } \\
\text { communication, and assessment tools has helped me improve my } \\
\text { learning. }\end{array}$ & 11.1 & 30.6 & 68.3 & $\begin{array}{l}3.59 \\
(0.88)\end{array}$ \\
\hline $\begin{array}{l}\text { Q7. During the last } 6 \text { weeks, I have applied my out-of-class experiences } \\
\text { and learned from practical applications. }\end{array}$ & 19.5 & 38.9 & 41.7 & $\begin{array}{l}3.34 \\
(0.87)\end{array}$ \\
\hline $\begin{array}{l}\text { Q8. During the last } 6 \text { weeks, I have explored my own strategies for } \\
\text { learning. }\end{array}$ & 13.9 & 33.3 & 52.8 & $\begin{array}{l}3.49 \\
(0.85)\end{array}$ \\
\hline $\begin{array}{l}\text { Q9. During the last } 6 \text { weeks, I have needed technical assistance for this } \\
\text { class. }\end{array}$ & 16.7 & 41.7 & 41.6 & $\begin{array}{l}3.47 \\
(0.88)\end{array}$ \\
\hline $\begin{array}{l}\text { Q10. During the last } 6 \text { weeks, the availability and access to technical } \\
\text { support and resources have helped me improve my learning. }\end{array}$ & 22.3 & 30.6 & 47.2 & $\begin{array}{l}3.54 \\
(0.96)\end{array}$ \\
\hline Q11. I would choose to take another course like this one. & 36.1 & 36.1 & 27.8 & $\begin{array}{l}2.91 \\
(1.11)\end{array}$ \\
\hline
\end{tabular}

Note. Items were adapted from "Effect of the flipped classroom model on a secondary computer applications course: Student and teacher perceptions, questions and student achievement," by (Johnson L, Renner J: Effect of the flipped classroom model on a secondary computer applications course: Student and teacher perceptions, questions and student achievement, Unpublished) 


\section{Data analyses}

The data obtained from the questionnaire and the pre-test and post-test were analyzed using SSPS 19.0. The data were first examined by descriptive statistics to explore mean, standard deviation, and frequency. Independent $t$-tests were applied to analyze the differences in the two groups' prior knowledge, SE and SRL, and their perceptions of the flipped-learning environment. Paired $t$-tests were applied to analyze the differences in SE and SRL of the experimental group. Analysis of covariance (ANCOVA) was then applied to test the variance in post-test learning performance in the two groups. Prior knowledge was added as a covariate. Finally, the data from the semi-structured interviews about students' perceptions of the flipped-learning environment were analyzed using MAXQDA 12.

\section{Results}

Students' participation via watching micro-lectures (videos) and doing exercises

As shown in the Fig. 4, the percentage of micro-lectures completed is higher than $60 \%$, indicating that students had a tendency to complete the videos when they engaged with them at all. Approximately $80 \%$ said they had watched more than half of the videos in their entirety during the experiment. Furthermore, the number of students who viewed all the videos reached the maximum in the second week.

Around 55\% of the students completed more than half of the online exercises (see Fig. 5). The second week, the number of students who completed all exercises stood at 33. However, over the subsequent weeks, there was a sharp fall to about 11 each time. The number of students who did not do exercises sharply rose from 1 to 15(41.6\%) in the third week, and that number remained stable for the following weeks.

The time distribution in the micro-lectures and exercises was different as the course went on. Students who interacted in the MOOC were motivated and interested in watching micro-lectures and doing exercises before the first two classes. This allowed students to complete a large percentage of videos initially. The exercises sometimes failed to engage students because clear explanations for the correct answers were not provided.

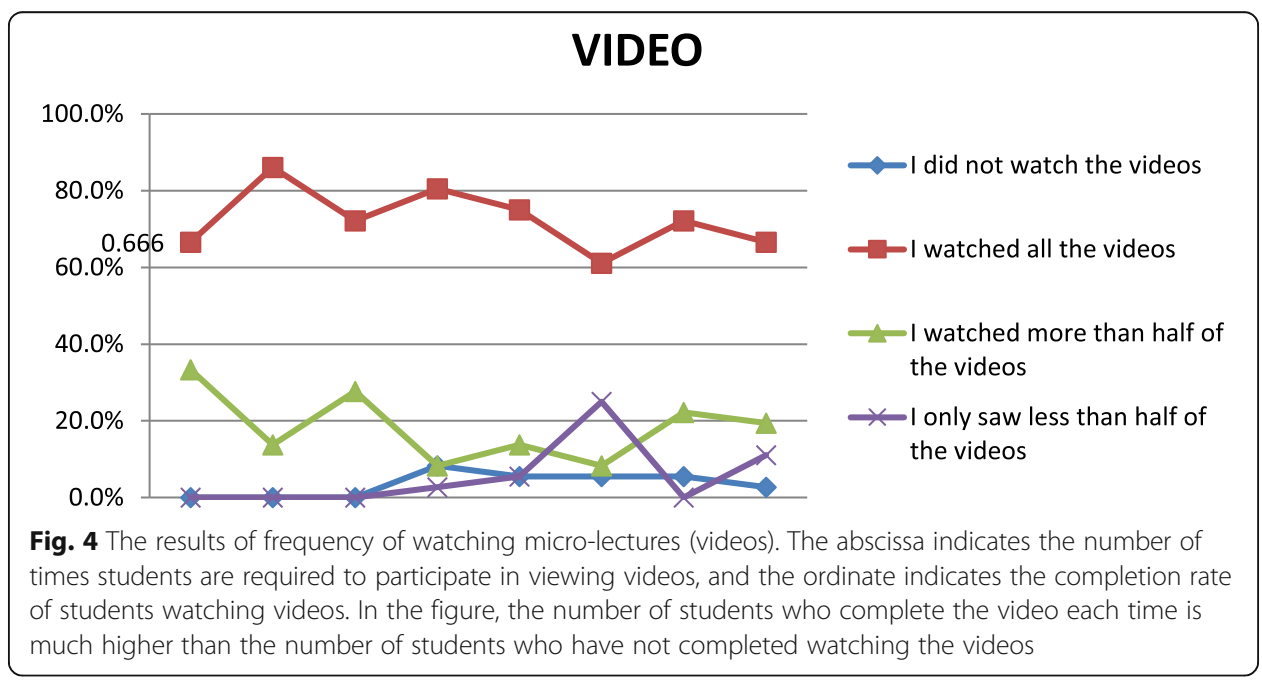




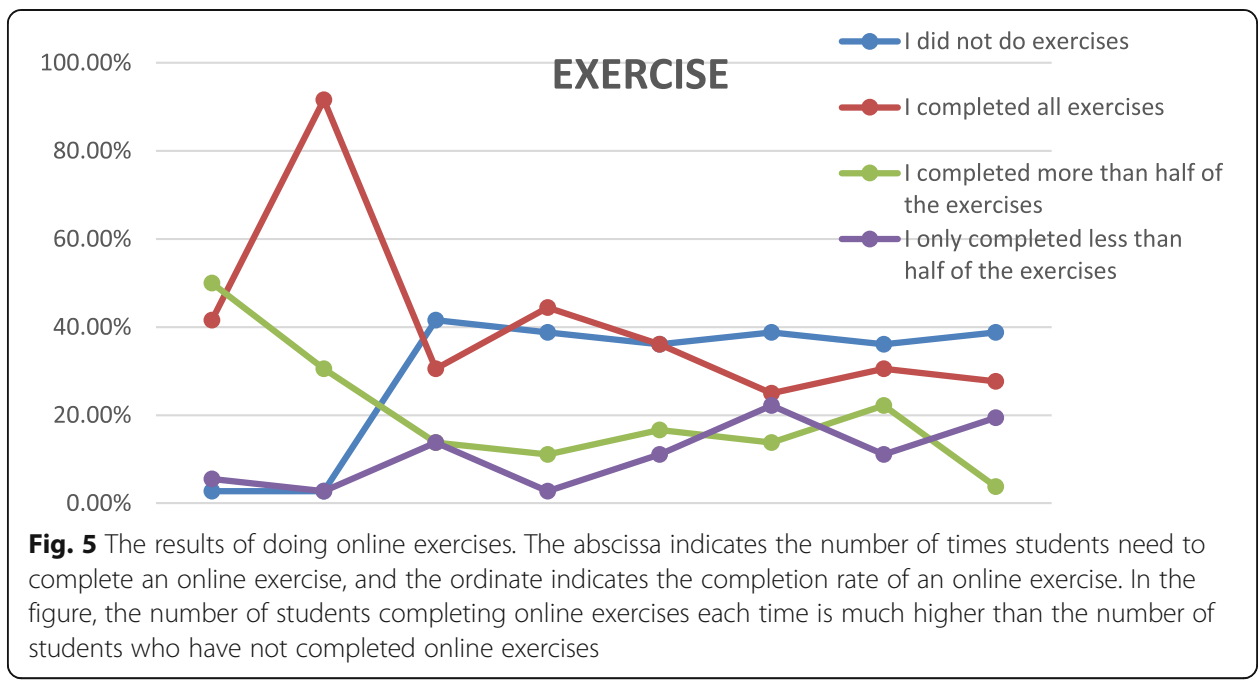

\section{Analysis of students' SE and SRL}

In order to investigate whether there were significant differences between pre-test and post-test SE and SRL in the flipped-learning setting, the test scores were compared using the paired samples $t$-test. The results showed no significant difference before and after the test for both the SE and SRL scales $(t=0.80, p>.05)$. Therefore, students' SE and SRL were not significantly different before and after flipped learning.

\section{Learning performance}

Before the experiment, a pretest was administered in the two groups to assess students' prior knowledge of the course content. The control group had a mean score of 37.70 and the experimental group had a mean score of 40.83. An independent $t$-test showed that students in the two groups had no significant difference in their pre-test scores $(t=0.74, p>05)$. This result suggests that students in both groups were similar with regard to their prior knowledge of the course content before the experiment. After carrying out the learning activity, we chose ANCOVA to analyze the results of post-test - for which the pretest score was the covariant, the post-test scores were the dependent variable, and the "different learning environment (two groups)" was the control variable-to examine the relationships between the post-test results of the two groups. The results of ANCOVA indicated that the experimental group $(M=73.43)$ and the control group $(M=67.11)$ differed significantly in their post-test scores $(t=4.90, p<.001)$ when controlling for the pre-test scores.

\section{Analysis of student experiences}

The results of the survey are presented in Table 1. We combined strongly disagree and disagree as negative responses, and agree and strongly agree as positive responses. Among the 11 items, 55.5\% of students' attitudes toward student-student interaction were positive. Only $22.2 \%$ of the respondents had a positive attitude to student-teacher interaction. Students were also asked about their engagement with the learning content and resources. Most of the respondents (80.6\%) felt positive that they had to work hard 
on this course during the preceding 6 weeks. The majority of respondents considered that they had learned a lot (63.9\%). Meanwhile, $68.3 \%$ of the respondents believed that the availability of course materials, communication, and assessment tools helped them improve their learning efficiency. Notably, however, only $27.8 \%$ of the respondents reported that they would like to continue to study in this way.

In order to further explain this result, we then conducted semi-structured interviews. Of the 37 students surveyed, ten participated in these interviews. The researchers coded each of the transcripts based on the six guiding interview questions, and the results are shown in Table 2.

More than half students $(70 \%)$ responded that this was the first time they had participated in this course. During this learning process, they were simply interested at the beginning. Afterwards, for various reasons, $80 \%$ students still preferred traditional face-to-face teaching. Almost all students (90\%) rated the micro-lecture quality highly; most indicated that they preferred to watch microlectures on the platform, to better understand a concept or textbook topic. What is more, some of the students had no difficulty in watching the videos, but did have problems in understanding them by themselves. Comparatively, only $40 \%$ of students perceived the quality of the online exercises to be generally at a high level. $90 \%$ of students' comments on student-student interactions and $80 \%$ of their comments on teacher-student interactions were positive. They considered that the flipped classroom gave them the opportunity to spend lots of time discussing their problems with the lecturer and their peers in class. $80 \%$ of students spent their out-of-class time watching micro-lectures, and $70 \%$ believed that flipped learning enabled them to learn more actively.

\section{Discussion}

With regard to RQ1 (To what extent do students participate in flipped learning, in terms of watching micro-lectures and doing online exercises?), students showed a good completion rate of watching micro-lectures. The results can be explained by the fact that the technology has been perceived positively and thus had a significant impact on students' participation. Although it was found that learner-technology fit affects student use, it is important to note that students in this research clearly believed that the MOOCs system had contributed to their learning. Regarding student utilization, the

Table 2 Students' experience of MOOC-based flipped learning

\begin{tabular}{lll}
\hline Subject & Topic & Count/percentage \\
\hline Overall experience & Reward & $7(70 \%)$ \\
Learning content & Shortage & $8(80 \%)$ \\
& Micro-lectures & $9(90 \%)$ \\
Learning interaction & Online exercises & $4(40 \%)$ \\
& Student-student interaction & $9(90 \%)$ \\
Learning motivation & Teacher-students interaction & $8(80 \%)$ \\
& Watching time & $8(80 \%)$ \\
Self-evaluation & attitude & $7(70 \%)$ \\
& Self-efficacy & $4(40 \%)$ \\
& Self-regulated learning & $3(30 \%)$ \\
\hline
\end{tabular}


survey results show that if students believe that the technology is beneficial in performing individual learning tasks and activities, they are more likely to spend energy and be more satisfied with the information. What is more, quality considerations are also prominent. Although some respondents had not experienced MOOCs previously, quality judgment usually depends on environmental factors such as the length of the course. Jordan (2015) found that these factors are positively related to registration, so a more substantial curriculum tends to result in a higher enrollment rate. The results can also be explained by the fact that Chinese undergraduates live in groups, usually four to eight people in one dormitory, and will watch micro-lectures together in the evening, which empowers students with a sense of being part of a team. Previous MOOC research has suggested that participants have a tendency towards group learning, and that social facilitation within the learning groups may make the acquisition of difficult concepts more enjoyable (Mackness, Mak, \& Williams, 2010). With regards to student participation in online exercises, tangible change can be seen after 2 weeks. Clow (2013) used a funnel metaphor to describe the relationship between participation in activities and completion rates in MOOCs. The funnel is defined by four stages, consciousness - registration - activity - progress, which are characterized by a sharp drop from one stage to the next. Our results indicate that most students claimed that completion rates were related to the ease of online practice and the accompanying explanation. When students realized that there was no detailed explanation of the exercises online, their interest declined dramatically. Our results indicate that the MOOC online exercises did not fully meet the students' needs.

For RQ2 (Will students' SE and SRL in the flipped-learning setting increase following completion of the course?), our results are not consistent with the findings of previous studies (e.g. Shea \& Bidjerano, 2010) that experience of a learning environment resulted in a change in level of SE. Some explanations can be put forward for this result. First, the six-week study period may be too short to detect changes in SE. In addition, changes in student variables may be compromised by the fact that students are working in an unfamiliar learning environment. In order to promote SRL, it is necessary not only to understand the regulatory procedures, but also to have insight into their determinants. The extent to which students will make use of SRL will to a large extent depends on their motivation (Pintrich, 2004; Zimmerman, 1989). By using controllable or autonomous motivational processes, students can develop their SRL (Vansteenkiste, Lens, \& Deci, 2006). In addition, Hart and Friesner (2004) mentioned that Chinese learners may feel that they are subservient to their teachers. Our interview results indicated that these students had just passed the college entrance examination and entered the university, so were already accustomed to teachers' arrangements for learning. Although some students participated in the flipped learning as required, they showed little sign of SRL in relation to viewing the micro-lectures, often only watched them when teachers announced the deadline in the class's online group.

Regarding RQ3 (What differences in learning performance between flipped learning and traditional learning can be observed after the course?), the results indicated that students studying in a flipped learning environment demonstrated better academic performance as compared to those in the traditional learning control group. The finding is consistent with other research (Baepler, Walker, \& Driessen, 2014; Thai, 2017). This is probably related to the fact that students actively engaged in viewing the micro- 
lectures, and because the course structure gave them more time outside of class to process the information introduced in the micro-lectures. Students benefited from the micro-lectures they watched in relation to this course, which supports the claim that micro-lectures are a valid means of achieving desired learning goals (Boateng, Boateng, Awuah, Ansong, \& Anderson, 2016). Moreover, online exercises provided a timely method of consolidating knowledge after watching the micro-lectures, which helped students better grasp what they had learned. Research shows that students perform better and have a better understanding of the concepts when classes are personalized and adapted to individual needs (Thyagharajan \& Nayak, 2007).

Our findings are consistent with previous studies which showed that flipped learning leads to increased student preparedness for classes (DeGrazia, Falconer, Nicodemus, \& Medlin, 2012; Findlay-Thompson \& Mombourquette, 2014), because it allows class time to be spent more effectively, and enables students to integrate the information and think critically about it (Enfield, 2013). Unlike a traditional classroom environment, the flipped approach helps to promote student engagement (Davies, Dean, \& Ball, 2013), and to encourage students to work out problems collaboratively. Our results support the characterization of active learning by Richardson, Abraham, \& Bond, (2012), who argued that flipped approach creates a positive impact on classroom learning through making students take the initiative and become more accountable because timely person-to-person guidance during the question and answer session with the teacher help the students feel like their personal issues and concerns are important. In addition, it was easy for the teacher to answer common questions in front of the entire class after the group discussion.

Turning to RQ4 (What are students' reported experiences of MOOC-based flipped classroom practice after the course?), the students gave high ratings to learning content and resources, learning interaction, and learning motivation and attitude. Comments on the learning content and resources out of class as a supplement of learning were positive. This suggests that micro-lectures and online exercises were widely accepted as a part of the students' learning process. However, findings related to the online exercises indicate that students had a poorer perception of the automated-correction exercises.

The results are consistent with the findings of RQ1. These exercises were singlechoice questions, and after completion students were only shown whether answers were correct or incorrect. Students' enthusiasm for the exercises diminished because of the absence of detailed explanations of the answers. With regard to learning interaction, the accessibility and attractiveness of the micro-lectures meant that students in the flipped learning group had the ability and desire to watch them at their convenience before classes. This resulted in more opportunities for the student-student interaction. Students would prefer the teacher to use class time for interaction, rather than spend the time on in-person lectures (Toto \& Nguyen, 2009). Furthermore, studentstudent interaction is vital to students' learning attitude (Eid \& Al-Jabri, 2016). These findings are partly supported by the student interviews. Students thought that their desire to perform better in group discussions led them to proactively view the microlectures and complete the practice exercises before the class to prepare themselves to answer classmates' questions during the group discussions. Students believed that learning motivation was thereby promoted through the group discussion. This process 
of helping each other solve problems gave students a sense of accomplishment and by doing so their learning motivation was enhanced. At the same time, other students indicated that the group discussions allowed them to contribute more willingly than they otherwise would have to.

In contrast, students gave a slightly less positive evaluation of the overall experience. This may be explained by the fact that the course we chose from the MOOCs used a one-size-fits-all approach to teaching and learning, and the content may have been updated before offering it to these students. Unlike other forms of online courses in traditional flipped learning, MOOCs may lack a well-defined structure in some cases or lack an adaption for the specific target groups, and rarely include a core role of teachers. Students who use them are normally engaging in self-directed learning, which is a completely different experience from formal classroom education. The findings of Israel (2015) suggest that some existing MOOCs are not designed to be embedded in traditional classrooms, which means that doing so while ensuring student satisfaction is a huge challenge. Localized, face-to-face courses and MOOCs have different characteristics and priorities; therefore, integrating MOOCs into a traditional learning environment involves attention to issues of coupling and cohesion (reference needed). As explained by Bruff et al. (2013), coupling refers to the type and degree of dependence between online and internal components of a mixed curriculum, while cohesion refers to the relevance of overall course content. It is difficult to find MOOCs that are compatible with traditional learning environments in terms of both coupling and cohesion.

\section{Conclusion and implications}

This study confirms the effectiveness of the MOOC-based flipped learning by applying a quasi-experiment research. The results show that a MOOC-based flipped learning design may improve student learning performance. Another significant finding is that the students have a positive experience of the micro-lectures, but a negative experience of the online exercises.

There are two important implications from this study which can provide a reference for teachers and MOOC designers in the future. First, when integrating MOOCs with their own methods, teachers need to consider how to ensure their teaching materials complement the online resources and help students to understand and master difficulties and key points of knowledge. This means that when teachers use integratedMOOCs to help students improve their learning, they need to pay particular attention to the selection of these courses to ensure that the chosen MOOC includes appropriate learning topics and themes. Second, the results indicate that micro-lectures are helpful to students, but that online exercises do not meet the needs of students due to the lack of detailed analysis of the answers. Accordingly, MOOC designers might attempt to include some detailed feedback on answers within the online exercises in order to better promote student learning.

Although the main objectives of the study have been achieved, the limitations of the present study need to be noted. The first limitation of our quasi-experiment is the effect that external conditions may have on the outcomes. The causal inference of the quasi-experiment is limited because the participants were not randomly assigned to a condition. It is often impossible for students in two classes of the university to choose experimental or control group voluntarily because of syllabus and curriculum. 
Therefore, in future research experiments that randomly assign individuals to conditions will be helpful to replicate or test our results. The second limitation is that the sample size of the quasi-experiment is not large, and it may be not applicable to infer the results to other cases or other conditions. Moreover, our MOOC design only focused on Chinese on-campus students. Future studies in other countries with different academic culture such as attitude, values, other ways of behaving, etc., may produce different results. In addition, due to time constraints, the analysis results and findings of this study need to be interpreted with caution. Because, in the short term, students' curious of using MOOC may affect the research results. Consequently, future research can be conducted to investigate the relevant issues with a larger sample size and a longer-time experiment.

\section{Acknowledgements}

Not applicable.

\section{Authors' contributions}

KW and CZ conceived and designed the study. KW performed the quasi-experiment and collected data. After that, KW wrote the draft paper. CZ reviewed and edited the manuscript. All authors read and approved the manuscript.

Funding

Not applicable.

\section{Availability of data and materials}

The datasets used and/or analyzed during the current study are available from the corresponding author on reasonable request.

Ethics approval and consent to participate

This study has gained the approval from the ethical committee of the department of chemistry at Shaanxi Preschool Teachers College.

\section{Competing interests}

The authors declare that they have no competing interests.

Received: 26 February 2019 Accepted: 9 July 2019

Published online: 26 August 2019

\section{References}

Baepler, P., Walker, J. D., \& Driessen, M. (2014). It's not about seat time: Blending, flipping, and efficiency in active learning classrooms. Computers \& Education, 78, 227-236.

Bandura, A. (1982). Self-efficacy mechanism in human agency. American Psychologist, 37, 122-147.

Barber, L. K., Bagsby, P. G., Grawitch, M. J., \& Buerck, J. P. (2011). Facilitating self-regulated learning with technology: Evidence for student motivation and exam improvement. Teaching of Psychology, 38(4), 303-308.

Bax, S. (2018). MOOCs as a new technology: Approaches to normalising the MOOC experience for our learners. In M. O. Jones, \& S. Smith (Eds.), Flipping the blend through MOOCs, MALL and OIL-new directions in CALL, (pp. 9-16). Coventry: Research-publishing.net.

Boateng, R., Boateng, S. L., Awuah, R. B., Ansong, E., \& Anderson, A. B. (2016). Videos in learning in higher education: assessing perceptions and attitudes of students at the University of Ghana. Smart Learning Environments, 3(1), 8.

Breslow, L., Pritchard, D. E., DeBoer, J., Stump, G. S., Ho, A. D., \& Seaton, D. T. (2013). Studying learning in the worldwide classroom research into edX's first MOOC. Research \& Practice in Assessment, 8, 13-25.

Bruff, D. O., Fisher, D. H., McEwen, K. E., \& Smith, B. E. (2013). Wrapping a MOOC: Student perceptions of an experiment in blended learning. Journal of Online Learning and Teaching, 9(2), 187-199.

Bulfin, S., Pangrazio, L., \& Selwyn, N. (2014). Making 'MOOCs': The construction of a new digital higher education within news media discourse. The International Review of Research in Open and Distributed Learning, 15(5), 291-305.

Chang, M. M. (2007). Enhancing web-based language learning through self-monitoring. Journal of Computer Assisted Learning, 23(3), 187-196.

Chen, Y., Wang, Y., Kinshuk, \& Chen, N. S. (2014). Is FLIP enough? Or should we use the FLIPPED model instead? Computers and Education, 79, 16-27.

Clow, D. (2013). MOOCs and the funnel of participation. In Proceedings of the third international conference on learning analytics and knowledge, (pp. 185-189). Leuven, (2013): LAK.

Davies, R. S., Dean, D. L., \& Ball, N. (2013). Flipping the classroom and instructional technology integration in a college-level information systems spreadsheet course. Educational Technology Research and Development, 61(4), 563-580.

DeBoer, J., Ho, A. D., Stump, G. S., \& Breslow, L. (2014). Changing "course" reconceptualizing educational variables for massive open online courses. Educational Researcher, 43(2), 74-84.

Downes, S. (2008). Places to go: Connectivism \& connective knowledge. Innovate: Journal of Online Education, $5(1), 6$.

Egbert, J., Herman, D., \& Lee, H. (2015). Flipped instruction in English language teacher education: A design-based study in a complex, open-ended learning environment. Tesl-Ej, 19(2), n2. 
Eid, M. I., \& Al-Jabri, I. M. (2016). Social networking, knowledge sharing, and student learning: The case of university students. Computers \& Education, 99, 14-27.

Enfield, J. (2013). Looking at the impact of the flipped classroom model of instruction on undergraduate multimedia students at CSUN. TechTrends, 57(6), 14-27.

Findlay-Thompson, S., \& Mombourquette, P. (2014). Evaluation of a flipped classroom in an undergraduate business course. Business Education \& Accreditation, 6(1), 63-71.

Firmin, R., Schiorring, E., Whitmer, J., Willett, T., Collins, E. D., \& Sujitparapitaya, S. (2014). Case study: Using MOOCs for conventional college coursework. Distance Education, 35(2), 178-201.

Fischer, G. (2014). Beyond hype and underestimation: Identifying research challenges for the future of MOOCs. Distance Education, 35(2), 149-158.

Francl, T. J. (2014). Is flipped learning appropriate. Journal of Research in Innovative Teaching, 71, 119-128.

Geist, M. J., Larimore, D., Rawiszer, H., \& Al Sager, A. W. (2015). Flipped versus traditional instruction and achievement in a baccalaureate nursing pharmacology course. Nursing Education Perspectives, 36(2), 114-115.

Gilboy, M. B., Heinerichs, S., \& Pazzaglia, G. (2015). Enhancing student engagement using the flipped classroom. Journal of Nutrition Education and Behavior, 47(1), 109-114.

Hao, Y. (2016). Exploring undergraduates' perspectives and flipped learning readiness in their flipped classrooms. Computers in Human Behavior, 59, 82-92.

Harrington, S. A., Bosch, M. V., Schoofs, N., Beel-Bates, C., \& Anderson, K. (2015). Quantitative outcomes for nursing students in a flipped classroom. Nursing Education Perspectives, 36(3), 179-181.

Hart, M., \& Friesner, T. (2004). Plagiarism and poor academic practice-a threat to the extension of e-learning in higher education? Electronic Journal on E-learning, 2(1), 89-96.

Israel, M. J. (2015). Effectiveness of integrating MOOCs in traditional classrooms for undergraduate students. The International Review of Research in Open and Distributed Learning, 16(5).

Jordan, K. (2015). Massive open online course completion rates revisited: Assessment, length and attrition. The International Review of Research in Open and Distributed Learning, 16(3), 341-358.

Kaplan, A. M., \& Haenlein, M. (2016). Higher education and the digital revolution: About MOOCs, SPOCs, social media, and the cookie monster. Business Horizons., 59(4), 441-450.

Kim, G. J., Patrick, E. E., Srivastava, R., \& Law, M. E. (2014). Perspective on flipping circuits I. IEEE Transactions on Education, 57(3), 188-192.

Kong, S. C. (2014). Developing information literacy and critical thinking skills through domain knowledge learning in digital classrooms: An experience of practicing flipped classroom strategy. Computers \& Education, 78, 160-173.

Lai, C. L., \& Hwang, G. J. (2016). A self-regulated flipped classroom approach to improving students' learning performance in a mathematics course. Computers \& Education, 100, 126-140.

Lee, S. W. Y., \& Tsai, C. C. (2011). Students' perceptions of collaboration, self-regulated learning, and information seeking in the context of internet-based learning and traditional learning. Computers in Human Behavior, 27(2), 905-914.

Leis, A., Cooke, S., \& Tohei, A. (2015). The effects of flipped classrooms on English composition writing in an EFL environment. International Journal of Computer-Assisted Language Learning and Teaching (IJCALLT), 5(4), 37-51.

Li, Y., Zhang, M., Bonk, C. J., Guo, J., \& Guo, Y. (2015). Integrating MOOC and flipped classroom practice in a traditional undergraduate course: Students' experience and perceptions. International Journal of Emerging Technologies in Learning, 10(6), 4-10.

Lin, Y. N., Hsia, L. H., Sung, M. Y., \& Hwang, G. H. (2018). Effects of integrating mobile technology-assisted peer assessment into flipped learning on students' dance skills and self-efficacy. Interactive Learning Environments, 1-16. https://doi.org/1 $0.1080 / 10494820.2018 .1461115$

Littlejohn, A., Hood, N., Milligan, C., \& Mustain, P. (2016). Learning in MOOCs: Motivations and self-regulated learning in MOOCs. The Internet and Higher Education, 29, 40-48.

Mackness, J., Mak, S., \& Williams, R. (2010). The ideals and reality of participating in a MOOC. In Proceedings of the Seventh International Conference on Networked Learning, (pp. 266-275). Lancaster: University of Lancaster.

Martin, F. G. (2012). Will massive open online courses change how we teach? Communications of the ACM, 55(8), 26-28.

Moraros, J., Islam, A., Yu, S., Banow, R., \& Schindelka, B. (2015). Flipping for success: Evaluating the effectiveness of a novel teaching approach in a graduate level setting. BMC Medical Education, 15(1), 1.

Pintrich, P. R. (2004). A conceptual framework for assessing motivation and self-regulated learning in college students. Educational Psychology Review, 16, 385-407.

Richardson, M., Abraham, C., \& Bond, R. (2012). Psychological correlates of university students' academic performance: A systematic review and metaanalysis. Psychological bulletin, 138(2), 353.

Roach, T. (2014). Student perceptions toward flipped learning: New methods to increase interaction and active learning in economics. International Review of Economics Education, 17, 74-84.

Shea, P., \& Bidjerano, T. (2010). Learning presence: Towards a theory of self-efficacy, self-regulation, and the development of a communities of inquiry in online and blended learning environments. Computers \& Education, 55(4), 1721-1731.

Sowa, L., \& Thorsen, D. (2015). An assessment of student learning, perceptions and social capital development in undergraduate, lower-division STEM courses employing a flipped classroom pedagogy. In Presented at the 122nd ASEE Annual Conference \& Exposition. Seattle: American Society for Engineering Education.

Strayer, J. F. (2012). How learning in an inverted classroom influences cooperation, innovation and task orientation. Learning Environments Research, 15(2), 171-193.

Thai, N. T. T., De Wever, B., \& Valcke, M. (2017). The impact of a flipped classroom design on learning performance in higher education: Looking for the best "blend" of lectures and guiding questions with feedback. Computers \& Education, 107, 113-126.

Thyagharajan, K. K., \& Nayak, R. (2007). Adaptive content creation for personalized e-learning using web services. Journal of Applied Sciences Research, 3(9), 828-836.

Toto, R., \& Nguyen, H. (2009, October). Flipping the work design in an industrial engineering course. In 2009 39th IEEE Frontiers in Education Conference (pp. 1-4). IEEE.

Tucker, B. (2012). The flipped classroom. Education Next, 12(1), 82.

Tune, J. D., Sturek, M., \& Basile, D. P. (2013). Flipped classroom model improves graduate student performance in cardiovascular, respiratory, and renal physiology. Advances in Physiology Education, 37(4), 316-320. 
Vansteenkiste, M., Lens, W., \& Deci, E. L. (2006). Intrinsic versus extrinsic goal contents in self-determination theory: Another look at the quality of academic motivation. Educational Psychologist, 41(1), 19-31.

Vighnarajah, Wong, S. L., \& Bakar, K. A. (2009). Qualitative findings of students' perception on practice of self-regulated strategies in online community discussion. Computers \& education, 53(1), 94-103.

Wu, W. C. V., Hsieh, J. S. C., \& Yang, J. C. (2017). Creating an online learning community in a flipped classroom to enhance EFL learners' oral proficiency. Journal of Educational Technology \& Society, 20(2), 142-157.

Yang, Y. (2006). Effects of embedded strategies on promoting the use of self-regulation learning strategies in an online learning environment. Journal of Educational Technology Systems, 34, 257-269.

Zhao, L., Lu, Y., Huang, W., \& Wang, Q. (2010). Internet inequality: The relationship between high school students' internet use in different locations and their internet self-efficacy. Computers \& Education, 55(4), 1405-1423.

Zimmerman, B. J. (1989). A social cognitive view of self-regulated academic learning. Journal of Educational Psychology, 81(3), 329.

Zimmerman, B. J. (2001). Theories of self-regulated learning and academic achievement: An overview and analysis. In B. J. Zimmerman, \& D. H. Schunk (Eds.), Self-regulated learning and academic achievement: Theoretical perspectives, (pp. 1-37). Mahwah: Lawrence Erlbaum Associates Publishers.

\section{Publisher's Note}

Springer Nature remains neutral with regard to jurisdictional claims in published maps and institutional affiliations.

Submit your manuscript to a SpringerOpen ${ }^{\odot}$ journal and benefit from:

- Convenient online submission

- Rigorous peer review

- Open access: articles freely available online

- High visibility within the field

- Retaining the copyright to your article

Submit your next manuscript at $\boldsymbol{\nabla}$ springeropen.com 